\title{
TRAÇOS CARACTERIZADORES DO CONSTITUCIONALISMO CONTEMPORÂNEO: UM DEBATE SOBRE NEOCONSTITUCIONALISMO
}

Andressa Sloniec ${ }^{1}$

Raquel Fabiana Lopes Sparemberger ${ }^{2}$

\begin{abstract}
RESUMO: O presente trabalho possui a premissa de verificar os traços que são determinantes da era do constitucionalismo contemporâneo e a construção do cenário para o surgimento do neoconstitucionalismo. O arcabouço jurídico (neo)constitucionalista emerge a partir da dialética acerca da temática no final do século 19. O método de abordagem utilizado para o presente estudo foi o dialético, por ser um fenômeno de contradição inerente à temática, bem como o método de procedimento histórico e comparativo e a técnica de pesquisa bibliográfica.
\end{abstract}

Palavras-chave: Neoconstitucionalismo. Direitos fundamentais. Estado constitucional. Democracia. Contemporâneo.

\section{CHARACTERISTICS OF CONTEMPORARY CONSTITUTIONALISM: A DEBATE ON NEO-CONSTITUTIONALISM (S)}

\begin{abstract}
The present work has the premise of verifying the determinant features of the era of contemporary constitutionalism and the construction of the scenario for the emergence of neoconstitutionalism. The juridical (neo) constitutionalist framework emerges from the dialectic on the subject at the end of the 19th century. The method of approach used for the present study was the dialectic, as it is a phenomenon of contradiction inherent in the subject, as well as the method of historical and comparative procedure and the technique of bibliographic research.
\end{abstract}

Keywords: Neo-constitutionalism. Fundamental rights. Constitutional state. Democracy. Contemporary.

\footnotetext{
${ }^{1}$ Mestranda em Direito Público pelo Programa de Pós-Graduação em Direito da Fundação Escola Superior do Ministério Público (FESMP/RS), vinculada à linha de pesquisa Tutelas à Efetivação de Direitos Transindividuais, sob a orientação da professora Doutora Raquel Fabiana Lopes Sparemberger. E-mail: andressasloniec02@gmail.com.

${ }^{2}$ Doutora em Direito. Professora do Mestrado em Direito da Fundação Escola Superior do Ministério Público-RS. Professora do Mestrado em Direito da Universidade Federal de Rio Grande - Furg.
} 


\section{INTRODUÇÃO}

É perceptível que o Direito passou por inúmeras nuances nos últimos tempos no ordenamento jurídico, ou seja, numa perspectiva moderna que ficou acentuada a partir do século 19, o qual desencadeou a era do constitucionalismo do Estado de Direito e poderes limitados, bem como o respeito aos direitos fundamentais.

Parte-se de uma perspectiva de neoconstitucionalismo de Miguel Carbonnel, e, na primeira parte deste trabalho, será observado o constitucionalismo contemporâneo que emergiu a partir do século 19, precisamente no final da Segunda Guerra Mundial ${ }^{3}$, bem como os mais diversos conceitos sobre o que é constituição por autores elencados por Carbonell e a exposição sobre Direitos Fundamentais para Luigi Ferrajoli e Gustavo Zagrebelsky.

Para Guastini (2007, p. 15-16), o termo Constituição "é usado em linguagem legal (e política) com uma multiplicidade de significados”. Assim, explica o autor, a palavra Constituição varia de significado, pois o termo é usado pela filosofia política, a teoria do direito, o direito positivo, a teoria geral das fontes, a linguagem comum, pelo seu relacionamento hierárquico com outras fontes ou, mesmo, por sua forma de ser instituído ou modificado.

Já Comanducci (2007, p.41) fornece uma saída para a problemática intensa da “especificidade da interpretação constitucional” e sugere como alternativa recorrer a ferramentas de classificação metodológica. Ou seja, surgem conflitos em "uma configuração não compartilhada do objeto da Constituição que, por sua vez, deriva de opções metodológicas ou ideológicas anteriores”, e para salvar os referidos conflitos propõe uma classificação de modelos constitucionais. Conforme Comanducci, a Constituição pode ser classificada, de acordo com sua função, como norma ou como ordem. Ambos os critérios permitem focar o aspecto axiológico ou descritivo e sua função, norma ou "como" ordem dão origem a classificação em quatro modelos: ${ }^{4}$ a Constituição como, 1) um modelo axiológico de uma ordem; 2) um modelo descritivo de uma ordem; 3) um modelo axiológico de uma norma; e 4) um modelo descritivo de uma norma. (2007, p.42).

Sobre os direitos fundamentais de Luigi Ferrajoli (2011), está aqui uma apresentação resumida de todas as ideias que este autor teve nos últimos anos sobre o assunto. Assim, a mudança que o estado de direito passou na sua versão legislativa para o paradigma contemporâneo do Estado de direito constitucional, é sublinhada. Do mesmo modo, condensa a fórmula proposta por ele para determinar quais são os direitos fundamentais; ou seja, a questão de que os direitos fundamentais podem ser respondidos de três maneiras: o teórico legal irá responder de acordo com as características atribuídas aos direitos fundamentais, isto é, sua estrutura lógica; o positivista responderá seguindo ordens nacionais ou internacionais; e, finalmente, o filósofo político responderá com base em critérios normativos. Depois de indicar as notas sobre os direitos fundamentais, Ferrajoli (2011)

\footnotetext{
${ }^{3}$ CARBONELL, Miguel [et al]. Teoría del neoconstitucionalismo. Ensayos escogidos, Madrid, Editora Trotta-UNAM, Instituto de Investigaciones Jurídicas, 2007.

4 “A cada modelo, explica el autor, corresponde una forma específica de interpretar a la Constitución y cada teórico proporcionará una alternativa de interpretación según el modelo que asuma. Este autor concluye que no puede indicar una elección entre los diversos modelos pues su propuesta es de metajurisprudencia y no de dogmática jurídica” (CRUZ, 2007, p. 339).
} 
mostra como esses padrões têm efeito sobre temas polêmicos e tópicos: o direito à autodeterminação, as diferenças culturais, o relativismo cultural e, por fim, a globalização.

A segunda parte do presente trabalho traz uma exposição dialética dos temas controversos dos últimos anos. Owen Fiss (1992), por exemplo, faz um importante discurso em favor do estado ativista em termos de ser promotor de valores de liberdade de expressão, tendo como ponto de referência sua Constituição, e argumenta que seu sistema constitucional não garante, mas que promove um estado ativista.

Por outro lado, Gerardo Pisarello (2009), em um ensaio subsequente, aponta para vários temas a serem levados em conta pelas aspirações constitucionalistas. Certamente Pisarello (2009) enfatiza a necessidade de se preparar contra as armadilhas do discurso globalizado, mas sempre buscando sucesso em um constitucionalismo cosmopolita. Para alcançar esse sucesso, conforme o autor, é essencial abordar quatro pontos: necessidades básicas, multiculturalismo, ecologia e democracia.

Também abordar-se-á a exposição do autor Christian Courtis (2007, p.186) sobre “o aspecto jurídico da política social”, quando escreve sobre a questão dos direitos sociais. Consciente da nossa realidade latino-americana, Courtis exibe os desafios das nossas sociedades para desencadear a aspiração desses direitos sociais. Sabendo a inexequibilidade desta tarefa, porém, oferece alguns pontos de atenção estratégicos para alcançar "garantias institucionais" desses direitos. (2007, p. 186).

O objetivo deste trabalho é verificar os traços que caracterizaram a era do constitucionalismo contemporâneo e as conotações que surgiram referentes ao lema neoconstiticionalismo. A problemática do aludido tema de pesquisa, contudo, é saber o que vem a ser o neoconstitucionalismo na sua aplicação prática e na sua dimensão teórica. $\mathrm{O}$ método de abordagem utilizado para o presente estudo foi o dialético, ${ }^{5}$ por um fenômeno de contradição inerente à temática, bem como o emprego do método de procedimento histórico e comparativo ${ }^{6}$ e a técnica de pesquisa bibliográfica. ${ }^{7}$

\section{Estado de Direito: os direitos fundamentais em um Estado constitucional democrático}

\footnotetext{
${ }^{5} \mathrm{O}$ "método dialético - penetra o mundo dos fenômenos através de sua ação recíproca, da contradição inerente ao fenômeno e da mudança dialética que ocorre na natureza e na sociedade” (LAKATOS; MARCONI, 2003, p. 106, grifo nosso).

6 “O método histórico consiste em investigar acontecimentos, processos e instituições do passado para verificar a sua influência na sociedade de hoje, pois as instituições alcançaram sua forma atual através de alterações de suas partes componentes, ao longo do tempo, influenciadas pelo contexto cultural particular de cada época. Seu estudo, para urna melhor compreensão do papel que atualmente desempenham na sociedade, deve remontar aos períodos de sua formação e de suas modificações”. E “o método comparativo é usado tanto para comparações de grupos no presente, no passado, ou entre os existentes e os do passado, quanto entre sociedades de iguais ou de diferentes estágios de desenvolvimento” (LAKATOS; MARCONI, 2003, p. 107, grifo nosso).

7 “A pesquisa bibliográfica, ou de fontes secundárias, abrange toda bibliografia já tornada pública em relação ao tema de estudo, desde publicações avulsas, boletins, jornais, revistas, livros, pesquisas, monografias, teses, material cartográfico, etc., [...]” (LAKATOS; MARCONI, 2003, p. 183, grifo nosso).
} 
Observa-se o Estado-nação ${ }^{8}$ como forma de organização política formada por sistemas jurídicos nascidos e desenvolvidos no término da Idade Média. O constitucionalismo contemporâneo tem definido seus traços característicos desde o final da Segunda Guerra Mundial; desde então não tem permanecido como um modelo estático, pois está evoluindo cada vez mais e em muitos sentidos. Os fenômenos evolutivos têm trazido evidentes impactos, que se pode chamar de paradigma do Estado constitucional ${ }^{9}$ (CARBONELL et al., 2009, p. 9-10).

O constitucionalismo nunca foi considerado uma ideologia neutra. Desde seu surgimento histórico tem estado vinculado a uma série de valores, ${ }^{10}$ dos quais se sobressai a igualdade; ${ }^{11}$ não uma igualdade simplesmente formal, tomada como uma "tela decorativa" nos textos constitucionais; a igualdade que demanda o constitucionalismo contemporâneo é uma igualdade substancial, uma igualdade que possibilite, em termos reais, o exercício de liberdade e de direitos de todos os seres humanos (CARBONELL; VÁZQUEZ, 2009, p. 13).

É conveniente dispor sobre a justiça política como equidade, ${ }^{12}$ pois o uso dos termos Estado, Sociedade e Constituição acaba por englobar tais sistemas. Essa ideia de sociedade como um sistema equitativo de cooperação é, de fato, de fundamental estudo. Conforme Rawls (2000), constata-se pelo fato de ter sido o foco da crítica liberal nos séculos 17 e 18 e da crítica socialista à democracia liberal constitucional dos séculos 19 e 20, e atualmente do conflito entre liberalismo e conservantismo a respeito do direito à propriedade privada e da legitimidade de medidas políticas sociais ligadas ao que passou a ser chamado de welfare state (p. 65, grifo do autor). É viável destacar que os direitos fundamentais garantem a autonomia privada de sujeitos jurídicos apenas quando esses sujeitos se reconhecem mutuamente em seu papel de destinatários de leis, erigindo, destarte, um status que lhes possibilita a pretensão de obter direitos e de fazê-los valer reciprocamente (HABERMAS, 1997, p. 159, grifos do autor).

\footnotetext{
${ }^{8}$ Verifica-se uma concepção moderna para a definição de "Estado e "Nação” vista por Habermas, o qual dispõe que "Estado" é um conceito definido juridicamente: do ponto de vista objetivo, refere-se a um poder estatal soberano, tanto interna quanto externamente; [...] e socialmente refere-se ao conjunto de seus integrantes, o povo do Estado.” Já “Nações” são comunidades de ascendência comum. Raiz vigente durante a Idade Média e no início da Era Moderna (2002, p. 124-126).

${ }^{9}$ Miguel Carbonell dispõe que "De hecho, el Estado constitucional surge dando por resuelta la eventual diferencia entre Estado y Nación: las constituciones suponen que cada Estado en particular está compuesto por una sola Nación, por un solo Pueblo” (2000, p. 97).

${ }^{10}$ É válido fazer referência sobre o conceito de valor pela “utilização da expressão ‘valor’: a diferença entre a constatação de que algo tem um valor e que algo é um valor” (ALEXY, 2006, p. 147, grifo do autor).

${ }^{11} \mathrm{O}$ termo “igualdade” é destacado por Ronald Dworkin como um conceito infeliz e raso. Ou seja, “[...] todos terem a mesma quantidade de riqueza ao longo de toda a sua vida -, pois, quando entendemos a igualdade como um conceito criterial, nenhuma outra definição é plausível. Atualmente, mesmo os liberais consideram respeitável a tese de que a igualdade é um falso valor, pois o importante não é que todos tenham a mesma riqueza, mas que os mais pobres não tenham menos do que o necessário para levar uma vida decente, ou para evitar grandes desigualdades, ou alguma coisa do tipo” (2014, p. 529).

12 John Rawls faz uma formulação sobre a justiça política com o viés na equidade e dispõe de três características principais: a primeira é a concepção política moral (valores políticos) aplicada a uma democracia constitucional moderna, a segunda é a concepção política de justiça apresentada de forma autossustentável, e a terceira é a concepção política de justiça em cujo conteúdo estão implícitas ideias fundamentais visando à cultura política pública de uma sociedade democrática (2000, p. 53-56).
} 
Observa-se, segundo Ferrajoli, ${ }^{13}$ que a expressão “Estado de Direito” denota vários entendimentos, sendo apropriado destacar, no presente trabalho, o sentido formal da expressão, que designa em qualquer ordenamento que os poderes públicos são conferidos pela lei e exercidos por formas e procedimentos legalmente estabelecidos. Num sentido mais estrito, são "Estados de Direitos" aqueles ordenamentos nos quais os poderes, incluindo o Legislativo, estão vinculados a princípios substanciais, estabelecidos pelas normas constitucionais, como a divisão de poderes e os direitos fundamentais (FERRAJOLI, 2009, p. 13-14).

Diferem-se os "Estados de Direitos" em modelos normativos distintos: o modelo "paleo-iuspositivista del Estado legislativo de Derecho (o Estado legal)”, que surge com o nascimento do Estado Moderno como monopólio da produção jurídica, e o modelo "neoiuspositivista del Estado constitucional de Derecho (o Estado constitucional)," produto da difusão da Europa depois da Segunda Guerra Mundial, das Constituições rígidas ${ }^{14}$ e do controle de constitucionalidade das leis ordinárias. Esses modelos refletem das experiências históricas diferentes que trazem alguns paradigmas: $a$ ) a natureza e a estrutura do Direito; $b$ ) a natureza da ciência jurídica e; $c$ ) a jurisdição. Tais paradigmas marcam o Direito prémoderno, o Estado legislativo de Direito e o Estado constitucional do Direito, e determinam as suas transformações, que transitam de um marco para o outro (FERRAJOLI, 2009, p. 14, grifos do autor).

O Estado de Direito moderno nasce com a forma de Estado legislativo de Direito, a partir do momento em que alcança a realização histórica, com a afirmação do princípio da legalidade como critério exclusivo de identificação do Direito válido e antes ainda existente com a independência de sua valoração como justo. Em virtude desse princípio e suas codificações com sua atuação, uma norma jurídica é válida não por ser justa, mas por ter sido posta por uma autoridade de competência legislativa (FERRAJOLI, 2009, p. 16).

O iusnaturalismo (Direito Natural) e o positivismo jurídico (Direito positivo), "bien pueden entenderse como las das culturas y las expeciencias juridicas que estan en la base de estos dos opuestos paradigmas" (FERRAJOLI, 2009, p. 17, grifo nosso). O iusnaturalismo como corrente de pensamento exercia uma hegemonia sobre os sistemas jurídicos até meados do Século 20, e atuava como mecanismos para auxiliar na supressão das lacunas do direito positivo. O iusnaturalismo terá papel determinante na formação dos preceitos e valores constitucionais modernos.

A condição da validez das leis muda e não depende apenas de seu modo de produção, mas também da coerência de seu conteúdo com os princípios constitucionais. A existência das normas no paradigma paleo-iuspositivista não estaria associada com a justiça nem

\footnotetext{
${ }^{13}$ É viável destacar que Luigi Ferrajoli dispõe de suas ideias pelo garantismo. Conforme Maia, “Garantismo, pois, vem do verbo garantir. Seria, no entender de Ferrajoli, uma forma de direito que se preocupa com aspectos formais e substanciais que devem sempre existir para que o direito seja válido. Essa junção de aspectos formais e substanciais teria a função de resgatar a possibilidade de se garantir, efetivamente, aos sujeitos de direito, todos os direitos fundamentais existentes. É como se a categoria dos direitos fundamentais fosse um dado ontológico para que se pudesse aferir a existência ou não de um direito; em outras palavras, se uma norma é ou não válida” (MAIA, 2000, p. 42, grifos do autor).

${ }^{14}$ Riccardo Guastini define constituição rígida como escrita, protegida contra a legislação ordinária, no sentido de que as normas não podem ser revogadas, modificadas, senão por um procedimento especial de revisão constitucional, mas com pleno respeito ao procedimento de formação das leis. Por final, conclui que todas as constituições contemporâneas escritas e ao mesmo tempo são rígidas (2009, p. 50-51).
} 
mesmo com a sua validez, sendo possível que uma norma válida e vigente seja substancialmente inválida pelo contraste de seu significado com normas constitucionais, como, por exemplo, o princípio da igualdade ou os direitos fundamentais (FERRAJOLI, 2009, p. 18).

É válido destacar que existe interação entre as transformações institucionais e as transformações culturais. As filosofias jurídica e política são sempre um reflexo, um fator constitutivo, experiência jurídica concreta de seus respectivos momentos. O iusnaturalismo, em suas diversas variantes, foi a filosofia jurídica dominante da época pré-moderna, enquanto não perdeu o monopólio estatal da produção jurídica; o iuspositivismo ocorreu a partir das codificações e do nascimento do Estado moderno; o constitucionalismo é, hoje, ou está chegando a ser depois da introdução da garantia jurisdicional, uma forma rígida das constituições (FERRAJOLI, 2009, p. 19-20).

Salienta-se que uma constituição não serve para representar a vontade comum de um povo senão garantir o direito de todos ante a vontade popular. "Su función no es expressar la existencia de un demos," uma homogeneidade cultural, identidade coletiva, coesão social, mas ao contrário, a de garantir por intermédio de direitos, a convivência pacífica entre sujeitos e interesses diversos e virtualmente em conflito. O fundamento da sua legitimidade, a diferença do que ocorre com as leis ordinárias e as opções de governo, não residem num consenso de maioria, mas de um valor muito mais importante e prévio: a igualdade de todos em suas liberdades fundamentais e nos direitos sociais, ou seja, em direitos vitais conferidos a todos, como limites e vínculos, precisamente perante as leis e os atos de governo expressos nas “cotas” das maiorias (FERRAJOLI, 2009, p. 28, grifo do autor).

Observa-se que, para Zagrebelsky (2013), a expressão “Estado de direito” é uma das mais afortunadas da ciência jurídica contemporânea. A mesma contém uma noção genérica e embrionária, embora não seja um conceito vazio ou uma fórmula mágica. A regra da lei indica um valor e alude apenas a uma das direções de desenvolvimento da organização do Estado, mas não contém consequências precisas. O valor é a eliminação da arbitrariedade no campo da atividade estatal que afeta os cidadãos (p. 21).

Não há dúvida de que o estado de direito historicamente representou um dos elementos de concepções constitucionais liberais, embora não seja de todo evidente que é incompatível com outras orientações político-constitucionais. O estado de direito liberal, contudo, teve necessariamente uma conotação substantiva, relativa às funções e propósitos do Estado. Nesta nova forma de Estado, característica do século 19, o que se destacou, em primeiro plano, foi a proteção e promoção do desenvolvimento de todas as forças naturais da população, como um objetivo da vida dos indivíduos e da sociedade. A sociedade, com suas próprias exigências, e não a autoridade do Estado, começou a ser o ponto central para a compreensão do estado de direito; e a lei, como uma expressão de vontade do Estado capaz de se impor incondicionalmente em nome de interesses transcendente, começou a ser concebida como um instrumento de garantia de direitos (ZAGREBELSKY, 2013, p. 22-23).

Com uma visão da "lei como uma norma geral e abstrata", ${ }^{15}$ o autor afirma que a generalidade é a essência da lei no estado de direito. Com efeito, o fato de que a regra

${ }^{15}$ Nesse sentido, o autor dispõe que: "Vinculada a la generalidad estaba la abstracción de las leyes, que puede definirse como 'generalidad en el tiempo' y que consiste en prescripciones destinadas a valer indefinidamente y, por tanto, formuladas mediante ‘supuestos de hecho abstractos’. La abstracción respondía a una exigencia de la sociedad liberal tan esencial como la generalidad: se trataba de garantizar la estabilidad del orden jurídico y, 
legislativa opera contra todos os assuntos da lei, sem distinção, é necessariamente ligado a alguns postulados fundamentais do Estado de Direito, como a moderação do poder, a separação de poderes e a igualdade perante a lei. A regra da lei é um inimigo do excesso, isto é, do uso "não regulamentado" do poder. A generalidade da lei implica uma "normatividade média”, isto é, feita para todos, o que, naturalmente, contém uma garantia contra o uso desenfreado do próprio poder Legislativo (ZAGREBELSKY, 2013, p. 29).

Para o "Estado constitucional”, a importância da transformação deve levar a pensar em uma verdadeira mudança genética, em vez de apenas um desvio momentâneo esperando por uma restauração. A resposta aos grandes e sérios problemas de tal mudança é uma consequência, e, ao mesmo tempo, está contida na fórmula deste Estado constitucional. A novidade é que a mesma contém capital e afeta a posição da lei. A lei, pela primeira vez na época moderna, está sujeita a uma relação de adequação e, portanto, subordinação, a um mais alto estrato de direito estabelecido pela Constituição (ZAGREBELSKY, 2013, p. 3334).

Destarte, por si só é que essa inovação poderia ser apresentada e, de fato, foi, mas como uma simples continuação dos princípios de Estado de direito, que leva a suas últimas consequências o programa de uma completa sujeição ao direito de todas as funções ordinárias do Estado, incluindo o Legislativo. Com isso, pode-se afirmar que se realiza a forma mais completa possível do princípio do governo das leis, no lugar do governo dos homens, princípio frequentemente considerado uma das bases ideológicas que fundamentam o Estado de direito. Se, no entanto, as afirmações genéricas passam a se comparar aos personagens concretos do Estado de direito do século 19 com os do Estado constitucional atual, adverte-se que, mais que uma continuação, se trata de uma profunda transformação que afeta necessariamente a concepção da lei (ZAGREBELSKY, 2013, p. 33).

É possível observar três formas de contemplar a relação entre direitos humanos ${ }^{16} \mathrm{e}$ democracia: a ingênua, a idealista e a realista. Na concepção ingênua não existem conflitos entre direitos fundamentais e democracia; já na concepção realista existe um conflito marcado pela limitação e pela escassez - nela o povo e seus representantes políticos não estão totalmente interessados em auferir os direitos fundamentais de nenhum cidadão por meio de decisões parlamentárias majoritárias e por leis de maneira contrária; de acordo com a concepção realista, tida como a mais correta, a relação entre os direitos humanos e a democracia caracterizam-se por constatações opostas: “1) os direitos fundamentais são profundamente democráticos; 2) os direitos fundamentais são profundamente antidemocráticos” ${ }^{17}$ (ALEXY, 2009, p. 37-38).

por consiguiente, la certeza y previsibilidad del derecho. La abstracción, en efecto, es enemiga de las leyes retroactivas, necesariamente 'concretas', como también es enemiga de las leyes 'a término', es decir, destinadas a agotarse en un tiempo breve, y, en fin, es enemiga de la modificación demasiado frecuente de unas leyes por otras” (ZAGREBELSKY, 2013, p. 29-30).

${ }^{16}$ Destaca-se que Ronald Dworkin define o uso da expressão “direito humano" como trunfo, num sentido forte de direito político (2014, p. 507).

${ }^{17}$ Robert Alexy discorre sobre essa oposição quando afirma que os direitos fundamentais são profundamente democráticos porque asseguram o desenvolvimento e a existência das pessoas graças às garantias de liberdade e de igualdade, capaz de manter estável o procedimento democrático, e porque asseguram as condições para o funcionamento do processo democrático mediante a proteção da liberdade de opinião, pressão, radiodifusão, reunião e associação, assim como o direito de sufrágio e outras liberdades políticas. Diante disso, são 
Cabe interpretar os direitos fundamentais de modo que projetem o que todos os cidadãos consideram importante e que não sejam confiados à maioria parlamentar simples. Desta forma, o princípio democrático, de certo modo, se reconciliaria num plano mais elevado com os direitos fundamentais. Essa concepção é correta e falsa ao mesmo tempo. Falsa porque o que os cidadãos consideram importante depende de seus ideais, de seus representantes do bem, de suas convicções religiosas e de suas concepções de mundo. Neste momento, Alexy denomina como "concepción moral” esse denso e extremamente confuso conglomerado. Atualmente é um direito que as concepções morais dos cidadãos sejam diferentes em sua grande maioria. Enquanto um depende de uma rígida ética de produtividade e detesta o Estado social, ${ }^{18}$ o outro aprecia o prazer à liberdade e seu financiamento (2009, p. 39).

Denota-se que a cultura política de uma sociedade democrática é sempre marcada por diversidades, sejam elas culturais, religiosas, filosóficas e morais, conflitantes e irreconciliáveis, ou seja, estar-se-á aqui a falar sobre valores - valores de uma sociedade na qual Dworkin aborda a democracia como um valor, e dispõe que "se aceitássemos que ela não é um valor - que não há nela nada de intrinsecamente bom -, boa parte da nossa vida política seria tolice” (2014, p. 533). O liberalismo político vê essa diversidade como inevitável, a longo prazo, no exercício das faculdades da razão humana em instituições básicas livres e duradouras. Conforme Rawls (2000), resta "saber quais são os fundamentos da tolerância assim compreendida, considerando-se o fato do pluralismo razoável como resultado inevitável de instituições livres” (p. 45, grifo nosso).

Retoma-se a constitucionalização pelo do termo de Guastini (2009), que a define como um processo de transformação de um ordenamento ao término do qual o ordenamento em questão resulta totalmente “impregnado" pelas normas constitucionais. Um ordenamento jurídico constitucionalizado caracteriza-se por uma Constituição extremamente invasora, capaz de condicionar tanto a legislação quanto a jurisprudência e seu estilo doutrinal, a ação dos atores políticos, bem como as relações sociais (2009, p. 49, grifo nosso).

A Constituição é a norma fundamental que estabelece a delimitação do alcance das liberdades dos indivíduos e das competências dos órgãos do Estado, bem-entendido que a delimitação do escopo das liberdades deve significar a sua garantia e que das competições estaduais é limitação. Daí também a necessidade, do ponto de vista do constitucionalismo teórico, de defender o senso unívoco da racionalidade política. A “glória do Estado” somente é possível com a "liberdade política dos cidadãos", porque a eficiência e a liberdade, a utilidade e o controle, são apenas dois lados da mesma moeda. Isso também reforça o caráter supremo da Constituição, um personagem que não se baseia apenas em uma exigência de técnica jurídica ou na organização burocrática do Estado contemporâneo, mas em um princípio político que lhe confere coerência: soberania popular sobre o poder do Estado, o indivíduo sobre o estado, a legalidade grávida de legitimidade (REYES, 2013, p. 93).

Verifica-se que constituições não são mais que um manifesto político, cuja concretização é tarefa exclusiva do legislador: os tribunais não devem aplicar as normas

profundamente antidemocráticos porque desconfiam do processo democrático. Com a apresentação inclusa do Legislativo, privam o poder de decisão para a maioria parlamentariamente legitimada (2009, p. 38).

18 Sobre "Estado social” é importante ressaltar o pensamento de Zagrebelsky, dispondo que os personagens da nossa sociedade, condicionados por uma ampla diversificação de grupos sociais, dão origem a uma marca diferenciada de tratamentos normativos como implicação empírica do princípio da igualdade do chamado Estado social (2013, p. 37). 
constitucionais - carentes de qualquer efeito imediato - senão as normas que recorrem às leis. Um dos elementos essenciais do processo de constitucionalização é precisamente a difusão, sendo a cultura jurídica a ideia oposta; é dizer que a ideia de que toda norma constitucional - independentemente de sua estrutura ou de seu conteúdo normativo - é uma norma jurídica genuína, vinculante e suscetível de produzir efeitos jurídicos (GUASTINI, 2009, p. 53).

Destarte, afirmar que nenhuma constituição tem eficácia na sua totalidade, ou seja, que consiga atender a vida social e política de uma sociedade, possui certas limitações reconhecidas como "lacunas" no texto constitucional. Pode-se garantir que qualquer lacuna, em qualquer texto normativo, não depende apenas do texto como tal - depende de como está interpretado o texto em questão, uma vez que todo texto normativo é suscetível a diversas interpretações. Em particular, sucede frequentemente de um texto dado, segundo certa interpretação, apresentar uma lacuna, enquanto o mesmo texto, conforme uma interpretação distinta, não apresente lacuna alguma (GUASTINI, 2009, p. 54).

Numa interpretação extensiva, a Constituição pode ser interpretada ou sobreinterpretada de forma que se extraia normas implícitas, não expressas e idôneas, para regular qualquer aspecto da vida social e política. Resume-se que toda decisão legislativa está regida por uma ou outra norma constitucional. Não existe lei que possa escapar do controle de legitimidade constitucional, ou seja, não há espaço para a discricionariedade legislativa. Cabe salientar que a sobreinterpretação da Constituição pressupõe que a Constituição mesma seja entendida como vinculante (GUASTINI, 2009a, p. 54-55).

O estabelecimento de uma Constituição é apenas a consequência de uma maneira muito específica de entender a ordem política e, portanto, implica uma tentativa de racionalização, isto é, organizar um tipo de Estado congruente com essa ordem que é considerada um modelo ou, pelo menos, é preferível. Daí a impropriedade de expressões como as de "Constituição Real” ou “Constituição Sociológica”, que tendem a ser contidas na maioria dos casos, além de uma certa confusão entre a ordem social e a ordem política, uma concepção contraditória de acordo com a ordem política e jurídica, que é a emanação simples da ordem social e, por sua vez, a ordem social deve ser garantida com certa ordem política e jurídica (REYES, 2013, p. 87).

Com isso, esquece-se, por um lado, a vocação transformadora da ordem social que a Constituição tem e, por outro, seu caráter paradoxal inevitável, porque, em virtude de seu significado simbólico indubitável, a Constituição não é apenas o reflexo de uma ordem, mas também um instrumento para tentar legitimar, com o qual, às vezes, a segunda tarefa prevalece sobre a primeira, embora de uma maneira muito diferente da imaginada pelo suposto "realismo". Isso ocorre quando a Constituição, ficando fictícia do ponto de vista sociológico, é "real” do ponto de vista político. Certamente, isso não reflete a realidade social, mas serve para manter essa realidade como ela é, isto é, suas funções verdadeiras são latentes e não se manifestam, mas também não deixam de ser efetivas (REYES, 2013, p. 87).

Sob a ótica de Comanducci, percebe-se um constitucionalismo moderno, entendido como uma ideologia jurídica e dividida em "três tricotomias", ${ }^{19}$ conforme destacado pelo

${ }^{19}$ É possível entender que as dicotomias feitas pelo autor têm o condão de dispor que o constitucionalismo dos contrapoderes é concebido por uma ideologia que requer um tipo completo de separação de poderes. Os poderes estatais são delegados, divididos e se limitam entre eles, com o fim de garantir os direitos individuais fundamentais do povo soberano. Os poderes, aqui, são meras funções do Estado: estão legitimados porque 
autor. A primeira dicotomia é apresentada em modos diversos, podendo-se distinguir entre constitucionalismo em sentido amplo e constitucionalismo em sentido estrito; a segunda dicotomia é a que existe entre constitucionalismo dos contrapoderes e constitucionalismo de regras; e a terceira dicotomia é a que existe entre constitucionalismo reformista e constitucionalismo revolucionário. Destarte, é por essas dicotomias que a função principal da Constituição não é de assegurar os direitos individuais e universais, "sino la de ofrecer sanción jurídica a un compromiso político estipulado por facciones que luchan para mantener o para conquistar el poder” (2009, p. 76-79).

\section{Neoconstitucionalismo(s): novos tempos para o Estado constitucional}

Num primeiro momento é passível de ser debatido o uso corrente do termo "neoconstitucionalismo" 20 para designar uma situação que se situa além do positivismo jurídico e do iusnaturalismo, objetivo que supõe discutir sobre as relações entre constitucionalismo e democracia, ${ }^{21}$ além de apresentar uma objeção ao neoconstitucionalismo (BARBERIS, 2009, p. 259, grifo nosso).

O termo neoconstitucionalismo, empregado com frequência em todo debate filósofojurídico, encaminha, de forma evidente, ao constitucionalismo, expressão por sua vez usada para indicar ao menos três coisas distintas, ainda que conectadas entre si. Num primeiro sentido, muito abrangente, "constitucionalismo" remota ao antigo ideal de governo das leis, o bem do Direito; em um segundo sentido, mais estrito, designa a tradução propícia dos séculos 18 e 19 de este modelo de ideia de Constituição como instrumento para limitar o poder político; em um terceiro sentido - estritíssimo, e não adequado ao todo - indica o Direito constitucional (BARBERIS, 2009, p. 259-260, grifo nosso).

Posta a posição filosófico-jurídica denominada neoconstitucionalismo, ao menos em seus primeiros sentidos do termo, parece existir razões suficientes para admitir este uso ainda não consolidado de neoconstitucionalismo (BARBERIS, 2009, p. 260). Por outro lado, o termo "neoconstitucionalismo" faz referência a uma determinada teoria do Direito, que defendeu, em um passado recente, essas mudanças e deu conta delas em termos bastante positivos ou até mesmo de forma complementar (CARBONELL et al., 2009, p. 9-10).

representam por inteiro o povo e atuam em nome do povo. No caso do constitucionalismo dos contrapoderes, este é concebido pelo governo monárquico. Os freios e contrapesos são estabelecidos entre órgãos que representam os diferentes interesses dos distintos grupos ou classes sociais (COMANDUCCI, 2009, p.78-79).

20“'Por 'neoconstitucionalismo', como já adiantamos, não deveriam ser entendidas nem doutrinas e nem instituições, como no caso de 'constitucionalismo', mas somente doutrinas: em especial a teoria ou doutrina do direito, intermediária ao jusnaturalismo e juspositivismo, pela qual entre direito e moral existiria uma interligação necessária, ainda que limitada aos Estados constitucionais. Segundo os neoconstitucionalistas, em outros termos, a tese juspositivista da separabilidade entre direito e moral valeria no máximo para o direito do Estado legislativo do século XIX: direito cuja fonte principal, senão única, era a lei. A mesma tese não valeria mais, ao contrário, para o Estado constitucional do século XX, onde não apenas a fonte principal do direito é a constituição, mas a totalidade do direito é constitucionalizada, refreada por princípios e valores constitucionais” (BARBERIS, 2006, p. 21).

${ }^{21}$ Barberis salienta que admitir a recíproca autonomia e o possível conflito entre valores jurídicos e morais permite não apenas perseguir o objetivo de uma relação equilibrada entre os diversos âmbitos da prática, mas também evitar o perigo da tirania dos valores (2009, p. 278). 
Como teoria, o neoconstitucionalismo representa uma alternativa com respeito à teoria iuspositivista tradicional: as transformações sofridas pelo objeto de investigação fazem com que esta não reflita mais a situação real dos sistemas jurídicos contemporâneos. Em suma, o estatalismo, o legicentrismo e o formalismo interpretativo, não parecem sustentáveis. (COMANDUCCI, 2009, p. 83). Para entender o desenvolvimento posterior do neoconstitucionalismo, e o próprio trânsito do constitucionalismo ao neoconstitucionalismo, é preciso levar em consideração um fenômeno que nos anos 60 não havia se manifestado ainda em toda sua extensão: o processo cada vez mais frequente denominado “constitucionalização do Direito” (BARBERIS, 2009a, p. 262).

Conforme Ferrajoli (2011), em síntese, bem mais que no modelo neoconstitucionalista - que confia a solução das aporias e dos conflitos entre direitos à ponderação judicial, inevitavelmente discricionária, mesmo quando argumentada, enfraquecendo, assim, a normatividade das Constituições e a fonte de legitimação da jurisdição -, o paradigma do constitucionalismo rígido limita e vincula de modo bem mais forte o Poder Judiciário, em conformidade com o princípio da separação de poderes e com a natureza tanto mais legítima quanto mais cognitiva - e não discricionária - da jurisdição (p. 103).

Parte-se de uma perspectiva complexa da democracia constitucional, traços que caracterizam um viés do neoconstitucionalismo e proporcionam uma interpretação completa com base nos principais marcos, não obstante as questões e paradigmas históricos sobre democracia. Conforme Nino (1997), o constitucionalismo e a democracia combinam para formar um sistema de governo parecido, com o nome “democracia constitucional” (p. 13).

Observa-se que a dimensão histórica do constitucionalismo está, muitas vezes, oculta atrás do reconhecimento dos direitos em razão de suas circunstâncias. Por um lado, a preservação da constituição histórica e do sistema jurídico que deriva dela, supõe-se um instrumento para a proteção dos direitos. Além disso, a constituição histórica frequentemente reconhece um conjunto de direitos que permite que sejam considerados moralmente aceitáveis. Deste modo, a observância da constituição histórica coincide com o respeito a esses direitos. O reconhecimento de direitos numa constituição histórica pode, porém, ser menos que ideal em vários graus e, às vezes, a proteção dos direitos de uma pessoa requer a violação dos “mandatos” do sistema jurídico (NINO, 1997, p. 25).

Para Comanducci (2009, p. 75), a questão constitucionalismo e neoconstitucionalismo designa, numa primeira aceitação, uma ideologia e um método de análise do direito. Já numa segunda aceitação, por outro lado, alguns elementos estruturais de um sistema jurídico e político, que são descritos e explicados pelo (neo)constitucionalismo como ideologia. Nesta segunda concepção, “constitucionalismo” e "neoconstitucionalismo" designam um modelo constitucional, ou seja, um mecanismo normativo e institucional, realizado em um sistema jurídico-político historicamente determinado, que limita os poderes do Estado e protege os direitos fundamentais. ${ }^{22}$

Desta maneira, sobre os direitos sociais é possível observar que, em um primeiro argumento, de fato, opera no nível axiológico ou avaliador e afirma que não são moralmente

\footnotetext{
22 Para Perez Luño, "Los derechos fundamentales se presentan en la normativa constitucional como un conjunto de valores objetivos básicos y, al propio tempo, como el marco de protección de las situaciones jurídicas subjetivas” (2004, p. 20).
} 
ou politicamente conhecidos como direitos fundamentais, ou fundamentais como os chamados direitos individuais. A ideia básica é que os direitos sociais são baseados em valores diferentes e, em última análise, menos relevantes do que aqueles. De acordo com este ponto de vista, os direitos civis e políticos teriam uma forte conexão com valores, como a liberdade, ou com princípios, como a dignidade da pessoa. Os direitos sociais se (re)formulam através da construção dos princípios e valores sociais erigidos pela sociedade moderna. Assim estão ligados a outros direitos, como a igualdade material ou a solidariedade, cuja satisfação somente seria justificada quando a liberdade ou a dignidade pessoal tivessem sido devidamente garantidas (PISARELLO, 2009, p. 14).

Observa-se, pela teoria política contemporânea de Dworkin, certos conceitos interpretativos, como os de igualdade e liberdade. Nas "democracias maduras", quase todos acabam por reconhecer, numa qualidade de tese abstrata, que o governo deve tratar os governados com igual consideração e deve conceder-lhes as liberdades de que precisam para definir uma vida bem-sucedida para si próprios. Não há, portanto, concordância acerca de quais são os direitos mais concretos que decorrem desses direitos abstratos (2014, p. 504).

Quando se parte da ideia de Dworkin (2014) de que o direito é uma forma particular da atividade humana, Fiss (2001) dispõe que os atores políticos, muitas vezes, levantam questões de justiça, mas isso não acontece necessariamente. Afirma-se que certa ação ou política é boa ou é para o benefício da comunidade, e isso será suficiente para o campo da política. Às vezes é suficiente para um político dar às pessoas o que elas querem, simplesmente porque é o que as pessoas querem. Os juízes, por outro lado, não têm outra autoridade, exceto para decidir o que é justo, e obter o direito de fazê-lo a partir das regras procedimentais que cercam sua posição e limitam o exercício de seu poder. Insistem, no entanto, nessas diferenças entre lei e política e não implicam aqui negar que sejam importantes conexões entre ambos (p. 238).

A concepção moral de sociedade é geralmente criticada por não poder assimilar os ideais de comunidade fraterna, igualdade e democracia. Enquanto se afirma que o liberalismo está baseado em valores de autonomia, inviolabilidade e dignidade ${ }^{23}$ das pessoas, se alega que este ignora outros aspectos essenciais da condição humana. Os críticos argumentam, em primeiro lugar, que o liberalismo fala em reconhecer o papel de pertencer a uma comunidade e desempenhar esse papel na vida e na formação do caráter dos indivíduos para assim definir sua identidade, condicionando seu raciocínio moral e uma eleição de planos de vida. Em segundo lugar, o liberalismo dá um peso indevido à autonomia, entendida como uma liberdade meramente formal, negativa e protetora, sem levar em conta as reivindicações de igualdade e justiça social (NINO, 1997, p. 85).

Assim, a ideia de igualdade é vista como niveladora segundo Nino (1997), pois essa ideia tem uma validez independente, quando ela se aplica às condições que se referem à participação no processo democrático de discussão e tomadas de decisão. Além do direito combinado com valores de liberdade e igualdade, as tensões entre estes valores desaparecem completamente. Poderia alcançar-se um ponto no qual um excesso de obrigações positivas de promover a autonomia dos menos autônomos remova toda a possibilidade de os indivíduos desenvolverem autonomamente planos de vida (p. 93-94). Nesse sentido, conforme dispõe Dworkin (2014), “deve-se ter um governo do povo, pelo povo e para o

\footnotetext{
${ }^{23}$ É importante ressaltar a afirmação de Dworkin, de que “somente a democracia pode garantir a dignidade” (2014, p. 579).
} 
povo. O povo deve governar a si mesmo. Cada cidadão deve ter uma participação igual e significativa” (p. 579).

Courtis (2007, p. 185) exibe os desafios das nossas sociedades para desencadear a aspiração de direitos sociais. Sabendo da complexidade desta tarefa, porém, oferece alguns pontos de atenção estratégicos para alcançar "garantias institucionais” desses direitos. Os direitos civis e os direitos sociais não são tão acentuados quanto os defensores da reivindicação da doutrina tradicional atentam. A principal diferença apontada pelos defensores desta doutrina reside na distinção entre obrigações negativas e positivas: de acordo com essa linha de argumentação, os direitos civis se caracterizariam pelo estabelecimento de obrigações negativas para o Estado. Todos os direitos, sejam eles civis, políticos, econômicos ou culturais, prescrevem tanto obrigações negativas quanto positivas. Os direitos civis não estão esgotados por obrigações de abstenção por parte do Estado: requerem um comportamento positivo, como a regulamentação - para definir o escopo e as restrições desses direitos (ABRAMOVICH; COURTIS, 2005).

O uso do termo neoconstitucionalismo como teoria do Direito pode descrever as realizações da constitucionalização. Esse processo tem comportado uma modificação dos sistemas jurídicos contemporâneos com respeito aos existentes desde a sua instituição integral. O modelo de sistema jurídico que emerge a reconstrução do neoconstitucionalismo, está caracterizado também por uma Constituição denominada por Comanducci de "invasora”, pela positivização de um catálogo de direitos fundamentais, pela onipresença na Constituição de princípios e regras, e por algumas peculiaridades de interpretação e aplicação da lei (2009a, p. 83).

Pozzolo (2009) entende inexistente a tarefa do neoconstitucionalismo num passado legalista do Estado de Direito, uma vez que imagina essa sociedade política em si mesma unida e pacífica, mas na contemporânea comunidade política - diversificada e multicultural - o que deveria assegurar a realização deste dever seria o princípio de constitucionalidade. A constitucionalização do ordenamento jurídico, de fato, não representaria a mera introdução de uma instância mais elevada de soberania dentro do esquema "piramidal" do ordenamento, e não representaria uma mera substituição de soberania legislativa com a soberania abstrata da Constituição, mas determinaria uma mutação qualitativa do Direito por inteiro (2009, p. 199).

Para concluir a dialética sobre as novas premissas do neoconstitucionalismo exposta nos tópicos anteriores, é válido ressaltar uma perspectiva sociológica sobre a temática que lhe envolve. O sociólogo Zygmunt Bauman (2000), em sua obra Em busca da Política, discorre sobre a democracia liberal ${ }^{24}$ como uma das mais poderosas utopias modernas que desenharam o modelo que deveria estruturar e governar uma boa sociedade ou, pelo menos, desenhar uma sociedade garantida contra algumas deficiências. Quando se fala de utopia ou realismo, pode-se afirmar que a democracia liberal é uma ousada tentativa de realizar um

\footnotetext{
${ }^{24}$ Outras perspectivas do autor sobre democracia liberal é que, “tanto na sua versão visionária quando na sua versão prática, é uma tentativa de manter a eficiência política do Estado no seu papel de guardião da paz e de mediador entre os interesses do grupo e dos indivíduos, permitindo a livre formação dos grupos e a livre autoafirmação dos indivíduos e sua livre escolha do estilo de vida que quiserem seguir. [...] A democracia liberal, em outras palavras, aspira à quadratura de um dos mais notórios círculos dentre os menos enquadráveis - para preservar simultaneamente a liberdade de agir do Estado, dos indivíduos e de suas associações, ao mesmo tempo que faz da liberdade de cada um, sua condição para a liberdade dos outros” (BAUMAN, 2000, p. 157-158).
} 
equilíbrio excessivamente difícil, sendo uma tarefa que poucas sociedades assumiram em outros tempos e lugares e que, de fato, nenhuma conseguiu materializar, quanto mais tornar seus resultados seguros e duradouros (p. 157).

Diante deste cenário, o resultado global são as atuais “condições fluidas de anomia generalizada e rejeição das normas” em todas as suas versões. De fato, a distância entre o ideal de democracia liberal e sua versão real aumenta ao invés de diminuir. Precisa-se percorrer um longo caminho "antes de sequer pensarmos em alcançar uma sociedade na qual 'os indivíduos reconheçam sua autonomia junto com os laços de solidariedade que os unem'” (BAUMAN, 2000, p. 159).

\section{CONCLUSÃO}

Diante do exposto, as questões referentes ao neoconstitucionalismo devem repelir as concepções mais radicais, mas não se pode esquecer dos princípios fundamentais de segurança jurídica, democracia e liberdade.

Luta-se por um neoconstitucionalismo que respeite o Estado democrático, que reconheça e valorize a irradiação dos valores constitucionais pelo ordenamento jurídico, pela atuação firme e racional de um Judiciário que assegure a proteção e promoção dos direitos fundamentais e dos pressupostos da democracia. Diante disso, uma concepção que conecte o Direito com as exigências de uma justiça e moralidade críticas, sem adentrar pelas categorias metafísicas do jusnaturalismo, já é superada pelo esforço do próprio positivismo clássico.

Nesse sentido, cabe ao neoconstitucionalismo pautar-se pela filtragem constitucional, sem descartar a importância das regras e da subsunção, mas abrindo espaço para a incidência dos princípios e da ponderação, tendo por objetivo racionalizar seu uso, conforme disposto por Zagrebelsky (2013).

Irradiar racionalmente o Direito Constitucional pelos mais diversos ramos do Direito é ventilar o ordenamento jurídico e manter a própria Constituição viva e concentrada com a sociedade que a regula. A Constituição regula, transforma e reconhece o povo, e esse reconhece e transforma a Constituição.

Por fim, apresentada a ligação entre Direito e moral no contexto teórico-normativo neoconstitucional, configura-se de suma importância a consideração de definir essa moral sobre bases críticas e racionalmente fundamentadas, para se evitar que o moralismo conservador seja superado pela legislação moderna, mas volte por meio da argumentação jurídica dos intérpretes, com lastro em conceitos que não se sustentam, trazendo à tona sua aplicação prática em sua vasta dimensão teórica. 


\section{REFERÊNCIAS}

ABRAMOVICH, Victor; COURTIS, Christian. Apuntes sobre la exigibilidad judicial de los derechos sociales - los derechos sociales en tanto derechos. Jura Gentium: Rivista di Filosofia del Diritto Internazionale e Della Política Globale, 2005. Disponível en: $<$ http://www.juragentium.org/topics/latina/es/courtis.htm>. Acesso em: 4 fev. 2018.

ALEXY, Robert. Teoria dos direitos fundamentais. Tradução Virgílio Afonso da Silva. 2. ed. 5. tiragem. São Paulo: Malheiros Editores, 2006.

ALEXY, Robert. Los derechos fundamentales em el Estado constitucional democrático. In: CARBONELL, Miguel [et al]. Neoconstitucionalismo(s). 4. ed. España: Editora Trotta, 2009.

BARBERIS, Mauro. Neoconstitucionalismo. Revista Brasileira de Direito Constitucional, vol. 1 , n. $7, \quad 2006 . \quad$ Disponível em: $<$ http://www.esdc.com.br/seer/index.php/rbdc/article/view/311>. Acesso em: 3 fev.2018.

BARBERIS, Mauro. Neoconstitucionalismo, democracia e imperialismo de la moral. In: CARBONELL, Miguel [et al]. Neoconstitucionalismo(s). 4. ed. España: Editora Trotta, 2009.

BAUMAN, Zygmunt. Em busca da política. Tradução Marcus Penchel. Rio de Janeiro: Editora Zahar, 2000.

CARBONELL, Miguel. Constitucionalismo, minorías y derecho. In: Isonomía: Revista de Teoría y Filosofía del Derecho, n. 12, p. 95-116, abr. 2000. Disponível em: $<$ http://www.cervantesvirtual.com/obra/constitucionalismo-minoras-y-derecho-0/>. Acesso em: 2 fev. 2018.

CARBONELL, Miguel [et al]. Teoría del neoconstitucionalismo. Ensayos escogidos, Madrid, Editora Trotta-UNAM, Instituto de Investigaciones Jurídicas, 2007.

CARBONELL, Miguel [et al]. Neoconstitucionalismo(s). 4. ed. España: Editora Trotta, 2009.

CARBONELL, Miguel; VÁZQUEZ, Rodolfo. Globalización y Derecho. 1. ed. Quito, Ecuador: Ministerio de Justicia y Derechos Humanos, 2009. 
COMANDUCCI, Paolo. Modelos e interpretación de la constituición. In: CARBONELL, Miguel [et al]. Teoría del neoconstitucionalismo. Ensayos escogidos, Madrid, Editora Trotta-UNAM, Instituto de Investigaciones Jurídicas, 2007.

COMANDUCCI, Paolo. Formas de (neo)constitucionalismo: un análisis metateórico. In: CARBONELL, Miguel [et al]. Neoconstitucionalismo(s). 4. ed. España: Editora Trotta, 2009.

COURTIS, Christian. Los derechos sociales em perspectiva: la cara jurídica de la política social. In: CARBONELL, Miguel [et al]. Teoría del neoconstitucionalismo. Ensayos escogidos, Madrid, Editora Trotta-UNAM, Instituto de Investigaciones Jurídicas, 2007.

CRUZ, Rodolfo Moreno; CARBONELL, Miguel (Ed.). Teoría del neoconstitucionalismo. Ensayos escogidos, Madrid: Trotta; Unam; Instituto de Investigaciones Jurídicas, p. 334, 2007.

CUESTIONES CONSTITUCIONALES: Revista Mexicana de Derecho Constitucional. Disponível em: <https://revistas.juridicas.unam.mx/index.php/cuestionesconstitucionales/article/view/5942>. Acesso em: 5 fev. 2018.

DWORKIN, Ronald. A raposa e o porco-espinho: justiça e valor. 1. ed. São Paulo: Editora WMF Martins Fontes, 2014.

FERRAJOLI, Luigi. Pasado y Futuro del Estado de Derecho. In: CARBONELL, Miguel [et al]. Neoconstitucionalismo(s). 4. ed. España: Editora Trotta, 2009.

FERRAJOLI, Luigi. Constitucionalismo Garantista e Neoconstitucionalismo. SIMPÓSIO DE DIREITO CONSTITUCIONAL DA ABDConst., 9., 2011, Curitiba. Anais... Curitiba, PR: ABDConst., ed. 22, 2011. p. 95-113. Disponível em: $<$ http://www.abdconst.com.br/revista3/anaiscompletos.pdf>. Acesso em: 3 fev. 2018.

FISS, Owen M. El Derecho recuperado. In: Doxa: Cuadernos de Filosofía del Derecho, n. 11, p. 233-246, 1992. Editora Alicante: Biblioteca Virtual Miguel de Cervantes, 2001. Disponible en: <http://www.cervantesvirtual.com/obra/el-derecho-recuperado-0/>. Acesso em: 4 fev. 2018. 
GUASTINI, Ricardo. Sobre el concepto de Constitución. In: CARBONELL, Miguel [et al]. Teoría del neoconstitucionalismo. Ensayos escogidos, Madrid, Editora Trotta-UNAM, Instituto de Investigaciones Jurídicas, 2007.

GUASTINI, Ricardo. La constitucionalización del ordenamento jurídico: el caso italiano. In: CARBONELL, Miguel [et al]. Neoconstitucionalismo(s). 4. ed. España: Editora Trotta, 2009.

HABERMANS, Jürgen. Direito e democracia: entre facticidade e validade I. Rio de Janeiro: Editora Tempo Brasileiro, 1997. Vol. 1.

A inclusão do outro: estudos de teoria política. São Paulo: Editora Loyola, 2002.

LAKATOS, Eva Maria; MARCONI, Marina de Andrade. Fundamentos de metodologia científica. 5. ed. São Paulo: Editora Atlas, 2003.

MAIA, Alexandre da. O garantismo jurídico de Luigi Ferrajoli: notas preliminares. Revista de Informação Legislativa, v. 37, n. 145, p. 41-46, jan./mar. 2000. Disponível em: $<$ http://www2.senado.leg.br/bdsf/handle/id/553>. Acesso em: 2 fev. 2018.

NINO, Carlos Santiago. La constituición de la democracia deliberativa. 1. ed. Barcelona, España: Editorial Gedisa, 1997.

POZZOLO, Susanna. Um constitucionalismo ambíguo. In: CARBONELL, Miguel [et al]. Neoconstitucionalismo(s). 4. ed. España: Editora Trotta, 2009.

PEREZ LUÑO, Antonio E. Los Derechos Fundamentales. 8. ed. España: Editora Tecnos, 2004.

PISARELLO, Gerardo. Defender y repensar los derechos sociales en tiempo de crisis. 1. ed. Barcelona, España: Editora El Tinter, SAL, 2009.

RAWLS, John. O liberalismo político. 2. ed. São Paulo: Editora Ática, 2000.

REYES, Manuel Aragón. Estudios de Derecho constitucional. 3. ed. Madrid, España: Editora Rústica, 2013. 
VIEIRA JÚNIOR, Dicesar Beches. Neoconstitucionalismo: definição, crítica e concretização dos Direitos Fundamentais. Revista Constituição e Garantia de Direitos, vol. $7,2014.2$ n. 2 Disponível em: $<$ https://periodicos.ufrn.br/constituicaoegarantiadedireitos/article/view/8007>. Acesso em: 2 fev. 2018.

ZAGREBELSKY, Gustavo. Del Estado de Derecho al Estado constitucional. Procesos constitucionales. Itália: Trujillo, 2013. Disponível em: $<$ https://edwinfigueroag.wordpress.com/2013/03/20/del-estado-de-derecho-al-estadoconstitucional-gustavo-zagrebelsky-pdf/>. Acesso em: 3 fev. 2018. 